\title{
A IMPORTÂNCIA DA ODONTOLOGIA NAS PESQUISAS EM CÉLULAS-TRONCO
}

\begin{abstract}
Vandré de Mesquita Taumaturgo", Evamiris de França Landim Vasques**, Viviane Maria Gonçalves de Figueiredo***
\end{abstract}

\begin{abstract}
Autor Correspondente: Vandré de Mesquita Taumaturgo-Email: vtaumaturgo@yahoo.com.br
* DDS, MsC e Prótese-UNP-RN, Especialista em Gestão do Trabalho e Educação em Saúde- UFRN-RN

** DDS, MsC, UNP-RN,PhD UNICSUL-S.P, Especialista em Prótese Dentária UECE-CE

*** DDS, MsC, PhD UNESP-SP, Especialista em Prótese Dentária COESP-PB
\end{abstract}

\begin{abstract}
Resumo
O uso de células para a realização de crescimento celular é chamado de Terapia celular. Esta é o conjunto de métodos e abordagens tecnológicas que utilizam células no tratamento de doenças. $\mathrm{A}$ terapia com células-tronco tem despertado grande interesse na comunidade científica devido à capacidade destas células indiferenciadas se diferenciarem em células de diversos tecidos. O objetivo principal para os pesquisadores desta área é determinar qual a fonte de célula-tronco é apropriada para uso terapêutico. Isto depende de diversos fatores como: a sua capacidade de proliferação e estabilidade citogenética, assim como suas características fenotípicas e seu potencial de diferenciação. A partir da evolução das pesquisas da Bioengenharia, a Odontologia tem contribuído em um papel bastante importante, na medida em que utilizam polpas dentárias, em especial as de dentes decíduos, de humanos como meio de crescimentos de células-tronco mesenquimais. Este achado utilizando este tipo de material foi a mais recente descoberta nas pesquisas científicas mundiais utilizando células-tronco. Este artigo apresenta uma revisão literária pertinente a este assunto com foco nas pesquisas mais atuais utilizando como material genético a polpa dentária.
\end{abstract}

Palavras-chave: Células-tronco; Polpa Dentária Decídua; Regeneração. 


\title{
THE IMPORTANCE OF ODONTOLOGY IN STEM CELLS RESEARCH
}

\begin{abstract}
Cell therapy methods consists of cell cultivation and growth for treatment of diseases. The scientific community has taken a keen interest in the stem cell therapy due to the stem cells' ability to preserve their own population and to differentiate into cells from various tissues. Finding a source of stem cells suitable for a therapeutic use depends on several factors, such as their ability to proliferate, their cytogenetic stability, as well as phenotypic characteristics and differentiation potential. In the evolution of bioengineering research, dentistry has been contributing in a very important role, in that it will scan dental pulps, especially the deciduous human teeth as a way of mesenchymal stem cells growth. These findings using pulp of deciduous teeth were the most recent discoveries in the scientific community using stem cells. This article has thus performed a literature review relevant to this important issue.

Keywords: Stem Cells; Dental Pulp deciduous; Regeneration.
\end{abstract}

\section{INTRODUÇÃO}

Atualmente, a Odontologia através de pesquisas de polpa dentária, especialmente, as de dentes decíduos, contribui para o avanço nos estudos mais atuais de células-tronco. Assim, as polpas de dentes apresentam características de células indiferenciadas com grande capacidade de auto renovação e de produzir pelo menos um tipo celular altamente especializado. ${ }^{(1)}$

A principal fonte de células-tronco é a medula óssea. Estas células têm a capacidade de se diferenciarem em células dos tecidos ósseo, adiposo, cartilaginoso e muscular, o que demonstra sua alta plasticidade. ${ }^{(2-5)}$

No entanto, Gronthos et al. ${ }^{(6,7)}$ constataram que as células de polpa dentárias são células que possuem a capacidade de auto renovação e de diferenciação em diversos tipos celulares. Ademais, as células-tronco da polpa dentária expressaram marcadores de precursores neurais e células gliais.

As últimas pesquisas científicas utilizando células-tronco foram as de polpa dentária de dentes decíduos. Existem evidências de que células-tronco de dentes decíduos são similares àquelas encontradas no cordão umbilical. Daí a importância da Odontologia em poder contribuir com a cultura de células-tronco. $^{(1,8)}$

Outras pesquisas demonstraram que células-tronco da polpa requerem um meio indutor apropriado e um arcabouço composto por hidroxiapatita/tricálciofosfato para induzir a formação de osso, cemento e dentina in vivo. ${ }^{(1)}$

Para que ocorra crescimento celular através de células-tronco fatores de crescimento devem ser utilizados para o desenvolvimento desse tipo de células. Esses fatores são proteínas secretadas extracelularmente que governam a morfogênese durante tais interações. ${ }^{(4)}$

Dentre os fatores de crescimento existentes, as proteínas morfogenéticas ósseas são suficientes para a formação de dentina terciária. ${ }^{(8)}$ Estas células ósseas chamadas BMPs são também encontradas no epitélio estrelado do órgão do esmalte durante a fase de capuz e estão associadas com a diferenciação dos ameloblastos e odontoblastos. ${ }^{(5)}$ 
Em suma, as células humanas isoladas da polpa dentária possuem fenótipo de células-tronco com capacidade multipotente de diferenciação e ainda é possível que as células-tronco da polpa humana e do ligamento periodontal estejam associadas com a microvasculatura. ${ }^{(1)}$

Com isso, consultando pesquisas envolvendo a área da Odontologia, este artigo científico apresenta uma revisão da literatura mais atual envolvendo células-tronco utilizando polpa dentária humana.

\section{MATERIAIS E MÉTODOS}

\section{DELINEAMENTO DE ESTUDO}

A revisão de literatura foi baseada em informações literárias publicadas em forma de artigos, livros e revistas científicas. Sendo de interesse principalmente, aquelas informações que tenham uma abordagem relevante, científica e atualizada no contexto da obra.

\section{BASE DE DADOS}

Bases de dados da internet como Bireme, Scielo, Lilacs, Medline, entre outros foram utilizados para levantamento de informações científicas sobre o tema proposto usando os descritores (células-tronco; polpa dentária decídua; regeneração) e (stem cells, dental pulp deciduous; regeneration). Não foi estabelecido nenhum período uma vez que, a literatura sobre este assunto é pequena.

\section{REVISÃO DE LITERATURA}

\section{CÉLULAS-TRONCO}

Células-tronco são células progenitoras capazes de se diferenciar em células de tecidos adultos especializados. Em relação às outras células do organismo, apresentam três características peculiares: são células indiferenciadas e não-especializadas, podem se multiplicar mantendo-se indiferenciadas por longo período (tanto in vivo quanto in vitro), de forma que poucas células são capazes de originar muitas populações semelhantes; e, diante de estímulos específicos, possuem a capacidade de se diferenciar em células maduras e funcionais de um tecido particular. ${ }^{(6)}$

Elas possuem a propriedade de divisão assimétrica, ou seja, originam células precursoras com capacidade restrita de diferenciação a um determinado tecido, ao mesmo tempo em que repõem a população de células-tronco com a produção de células indiferenciadas (auto-renovação). ${ }^{(8,9)}$

Inúmeras são as fontes de células-tronco e encontrar a mais apropriada para uso terapêutico depende da investigação de diversos fatores como suas características fenotípicas, potencial de diferenciação, sua capacidade de proliferação e estabilidade citogenética, quando expandidas in vitro. As células-tronco são classificadas como embrionárias ou adultas de acordo com sua fonte e estágio de desenvolvimento. ${ }^{(10)}$

\section{CÉLULAS-TRONCO EMBRIONÁRIAS}

As células-tronco embrionárias têm sua origem em embriões mamíferos no estágio de blastocisto, onde as células da massa interna, que vão originar todos os tecidos do indivíduo adulto, ainda estão indiferenciadas e podem estabelecer uma linhagem celular pluripotente. Possuem capacidade de se multiplicar em cultura sem perder a pluripotência e é possível induzir sua diferenciação em diversos tipos celulares específicos, o que faz das células-tronco embrionárias uma ferramenta de pesquisa poderosa e fonte promissora, quase ilimitada, de tecidos para transplante no tratamento de diferentes doenças. ${ }^{(6,7)}$

\section{CÉLULAS-TRONCO ADULTAS}

Células-tronco adultas, como todas as outras, possuem a propriedade de auto-renovação: fazem có- 
pias idênticas de si por longos períodos de tempo; e também podem dar origem a tipos de células maduras com morfologia característica e funções especializadas. ${ }^{(11)}$

Normalmente, as células-tronco geram um tipo de célula intermediária antes de se tornarem totalmente diferenciadas. Essas células em estágio intermediário são chamadas de células progenitoras ou precursoras, encontradas em tecidos fetais ou adultos, parcialmente diferenciadas e que se dividem dando origem a grupos diferenciados. ${ }^{(12)}$

Muitos experimentos que envolvem a plasticidade demonstram que células-tronco derivadas da medula óssea provenientes da mesoderme podem se diferenciar em outros tecidos provenientes da mesma camada, tais como: do músculo esquelético, do músculo cardíaco e do fígado; mas também foi relatado capacidade de diferenciação em tecido neural, que é derivado de camada embrionária diferente: a ectoderme. ${ }^{(11)}$

Dentre os principais tipos de células-tronco adultas identificadas temos as Células-Tronco Mesenquimais (CTM), que atuam no reparo e homeostase em vários tecidos do corpo como na regeneração de tecidos ósseos. São capazes de se diferenciar em vários tipos celulares, mas não em todas as células do organismo. ${ }^{(9,13)}$

\section{CÉLULAS-TRONCO MESENQUIMAIS}

As Células-Tronco Mesenquimais podem ser extraídas de diversos órgãos, expandidas em cultura como uma população aderente de células e induzidas a se diferenciar em múltiplos tipos celulares. ${ }^{(7)}$

Além das caracterizações fenotípicas e morfológicas para identificação das populações de células supostamente mesenquimais, avalia-se também a capacidade de se induzir a diferenciação in vitro em adipócitos, osteócitos e condrócitos. ${ }^{(9,13)}$

Baseada na observação de que as CTM podem passar por diferenciação adipogênica, osteogênica e condrogênica, surgiu a tentativa do uso de células mesenquimais para reparo tecidual in vivo. ${ }^{(9,13)}$
Aproximadamente um terço das CTM se diferencia com sucesso nas linhagens osteogênicas, condrogênicas e adipogênicas. A diferenciação in vitro em uma determinada linhagem celular requer o tratamento das células com uma mistura de fatores específicos. O meio basal, a densidade celular, a organização espacial, fatores de crescimento e citocinas são fundamentais no sucesso da diferenciação. ${ }^{(2)} A$ princípio a primeira fonte de células-tronco mesenquimais identificada foi a Medula Óssea (MO). Recentemente foi proposto que as CTM poderiam ser encontradas em uma grande variedade de tecidos, senão todos tecidos corporais. ${ }^{(14)}$

\section{CÉLULAS-TRONCO DE MEDULA ÓSSEA}

Na medula óssea três populações de células-tronco podem ser observadas: as hematopoiéticas, as mesenquimais (estromais) e provavelmente células progenitoras endoteliais. As hematopoiéticas são responsáveis pelo tecido sanguíneo e as células mesenquimais encontram-se imersas no estroma medular e podem dar origem a diferentes tipos celulares. ${ }^{(13)}$

As Células Mononucleares de Medula Óssea (CMO) compreendem as células hematopoiéticas e as não-hematopoiéticas, ambas possuindo plasticidade, potencial de auto-renovação e diferenciação e por isso tem sido sugerido a utilização de $\mathrm{CMO}$ em terapia celular. ${ }^{(15)}$

Foi demonstrado que o transplante de células da medula óssea pode resultar na completa e permanente reconstituição dos tecidos hematopoiéticos e que essas células podem se diferenciar em células epiteliais do fígado, baço, trato gastrintestinal, pele e pulmões. ${ }^{(10)}$

Outros estudos demonstraram que células da medula óssea possuem capacidade de se diferenciar em microglia e astrócitos após transplante em camundongo( ${ }^{(15)}$ e alguns trabalhos reportaram células de medula óssea expressando marcadores neuronais. ${ }^{(10)}$ 


\section{CÉLULAS-TRONCO DA POLPA DE DENTE HUMANO}

O dente se desenvolve na maxila e mandíbula dos mamíferos, variando a morfologia de acordo com a espécie e a localização, mas a estrutura se mantém similar sendo formado por: esmalte, cemento e dentina (juntos formam o tecido mineralizado que reveste a polpa), a polpa (formada por tecido conjuntivo vascularizado, com diferentes tipos celulares) e o periodonto (fixa os dentes nos ossos maxilares e mandibulares. ${ }^{(16)}$

A polpa dentária é derivada de componentes ectodérmicos e mesenquimais e é dividida em quatro camadas: a primeira, mais externa, composta de odontoblasto produzindo dentina; a segunda camada, pobre em células e rica em matriz extracelular; a terceira camada contém células progenitoras com plasticidade e pluripotência; e a camada mais interna, que compreende a área vascular e o plexo nervoso. ${ }^{(5)}$

Em 2000, Shi et. al. ${ }^{(12)}$ especularam que a polpa de dente adulta deveria, assim como a medula óssea, possuir uma população de células-tronco. Isolaram células da polpa de dente humano (terceiro molar) que comparadas com as células-tronco de medula óssea apresentaram heterogeneidade, multipotencialidade, capacidade de proliferação e de formação de colônias in vitro.

Em seguida a polpa de dente decíduo humano (dente de leite) foi também descoberta como uma rica fonte de CTM, capaz de se proliferar e diferenciar, podendo reparar estruturas dentárias danificadas e induzir regeneração óssea. ${ }^{(5)}$

Em meio de cultura onde foram isoladas células da polpa de dente humano (terceiro molar), composto por L-ascorbato-2-fosfato, glicorticóide e fosfato inorgânico, foi observada a capacidade de tais células formarem depósitos cálcicos in vitro. ${ }^{(5)}$

Após transplantação em ratos imunocomprometidos, as células-tronco pulpares exibiram habilidade de formar uma estrutura semelhante ao complexo dentino-polpa, composto de uma matriz de colágeno tipo I altamente organizada, perpen- dicular à camada tipo odontoblástica, e tecido fibroso contendo vasos sanguíneos, análogo à polpa encontrada em dentes humanos normais. ${ }^{(5)}$

Por não serem órgãos vitais, de fácil acesso e por ser um tecido que normalmente seria descartado, tornaram-se um atrativo para utilização em terapia celular. A extração do tecido pulpar é altamente eficiente, o local de coleta é fácil e as células possuem ampla capacidade de diferenciação e interatividade com biomateriais, tornando ideal para reconstrução de tecidos. ${ }^{(16)}$

Outros estudos testaram a capacidade do epitélio odontogênico de estimular células-tronco embriogênicas e mesenquimais, provenientes dos tecidos neurais e medula óssea, a expressarem genes do desenvolvimento dentário e, assim, substituírem o mesênquima dentário na bioengenharia. ${ }^{(10)}$

\section{CONSIDERAÇÕES FINAIS}

Atualmente sabe-se que a bioengenharia conseguiu alcançar grandes avanços no quesito do cultivo de células-tronco e a área que contribuiu bastante para esta ciência foi a Odontologia.

Muitos acreditavam que a ciência que estuda o elemento dentário se restringia apenas em realizar procedimentos estritamente relacionados ao tratamento das estruturas da cavidade bucal.

Hoje, através da polpa dentária encontrada como uma estrutura interna na parte coronária e radicular do dente será capaz proporcionar crescimento de células-tronco, ou seja, contribuir para uma ciência que objetiva o crescimento de células que não possuem estas características proliferativas, como as células nervosas.

Os grandes centros de ciência ao redor do mundo já apresentam resultados expressivos. No Brasil, as pesquisas científicas ainda estão em forma inicial, ainda muito incipientes. Estas estão situados no eixo Sudeste do Brasil.

Futuramente esse conhecimento trará maiores facilidades e com a união de centros de pesquisa iremos ter resultados mais expressivos. 


\section{REFERÊNCIAS}

1. Souza LM. Caracterização de células-tronco de polpa dental humana obtida de dentes decíduos e permanentes [dissertação]. Brasília: Universidade de Brasília; 2008.

2. Odorico JS, Kaufman DS, Thomson JA. Multilineage differentiation from human embryonic stem cell lines. Stem Cells.2001;19(3):193-204.

3. Nakashima M. Bone morphogenetic proteins in dentin regeneration for potential use in endodontic therapy. Cytokine Growth Factor Rev. 2005;16(3):369-376.

4. Harada H. et al. Epithelial stem cells in teeth. Odontology. 2002;90(1):1-6.

5. Baksh D, Song L, Tuan RS. Adult mesenchymal stem cells: characterization, differentiation, and application in cell and gene therapy. J Cell Mol Med. 2004;8(3):301-316.

6. Gronthos S. et al. Stem cell properties of human dental pulp stemcells. J. Dent. Res. 2002;81(8):531-535.

7. Gronthos S, Mankani M, Brahim J, Robey PG, Shi S. Postnatal human dental stem cells (DPSCs) in vitro and in vivo. Proc Natl Acad Sci USA. 2000;97:13.625-13.630.

8. Huang GTJ, Shagramanova K, Chan SW. Formation of odontoblast-like cells from cultured human dental pulp cells on dentine in vitro. J Endod. 2006; 32(11): 1066-1073.

9. Covas DT. Células-tronco mesenquimais In: Zago MA, Covas DT. Células tronco: a nova fronteira da medicina. São Paulo: Atheneu; 2006. p. 35-48.
10. Laino G, D'Aquino R, Graziano A, Lanza V, Carinci F, Naro F, Pirozzi G, Papaccio G. A new population of human adult dental pulp stem cells: a useful source of living autologous fibrous bone tissue (LAB). J Bone Miner Res. 2O05;2O(8):1394-4O2.

11. Miura M, Gronthos S, Zhao M, Lu B, Fisher LW, Robey PG, Shi SSHED: stem cells from human exfoliated deciduous teeth. Proc Natl Acad Sci USA. 2003;100(10):5807-5812.

12. Shi S, Bartold PM, Miura M. et al. The efficacy of mesenchymal stem cells to regenerate and repair dental structures. Orthod Craniofac Res. 2005;8:191-199.

13. Dahlin C, Linde A, Gottlow J, Nyman S. Healing of bone defects by guided tissue regeneration. Plast Reconstr Surg. 1988;81(5):672-676.

14. Pereira LV. Células-tronco embrionárias e clonagem terapêutica. In: Zago MA, Covas DT. Células-tronco: a nova fronteira da medicina. São Paulo: Atheneu; 2006. p. 21-34.

15. Perry BC, Zhou D, Wu X. et al. Collection, cryopreservation, and characterization of human dental pulp-derived mesenchymal stem cells for banking and clinical use. Tissue Eng Part C. 2008;14(2):146-156.

16. Wei X, Ling J, Wu L, Liu L, Xiao Y. Expression of mineralization markers in dental pulp cells. J Endod. 2007;33(6):703-708.

17. Zago MA. Células-tronco: origens e propriedades. In: Zago MA, Covas DT. Célulastronco: a nova fronteira da medicina. São Paulo: Atheneu; 2006. p. 3-20. 